\title{
Study on the modernisation of an extra-worn district heating (DH) system in Russia: low temperature DH and 4 more options processing
}

\author{
Stanislav Chicherin ${ }^{1}$, Lyazzat Junussova ${ }^{2}$ and Timur Junussov ${ }^{2}$ \\ ${ }^{1}$ Omsk State Transport University, Russia \\ ${ }^{2}$ Almaty University of Power Engineering and Telecommunications, Kazakhstan
}

\begin{abstract}
Modeling was performed on the base of the DH system located in Omsk, Russia, where the DH network temperature requirements are not met and design outdoor temperature of extreme $-37^{\circ} \mathrm{C}$ is. Surveyed investment in a transmission line to avoid penalties on disturbances is projected to have an original supply temperature of $150^{\circ} \mathrm{C}$ and is denoted as Case- 1 . The second idea (Case-2) envisages installing a heat pump and increasing the supply temperature in peak load periods during the heating season. The third option is to use of in-room terminal systems to provide heating to individual zones. Case- 4 assumes maintaining an ordinary DH network without using any energy-efficient alternative and significant repair which means that the system continuous working 'as is'. The fifth option introduces low temperature district heating (LTDH) concept featuring a low supply temperature and smart control. To sum up, this research indicates location of a heat pump and also shows how the piping system will be offset to allow the normal operation. This study presents a framework to represent, aggregate, dynamic thermal model and modernize a DH system based on a high-level equation-based simulation software and a five-option feasibility study.
\end{abstract}

\section{Introduction}

Kuprys \& Gatautis [1] reported Government support for multi-storey residential buildings' renovation project in Lithuania. Each energy demand can be met either from the same type of energy carrier or from another type of energy carrier using the energy conversion applications [2]. Retrofitting to electricity is an efficient auxiliary heating solution in Scandinavian countries [3]. Such a renovated system may operate at lower supply temperature levels as more low-energy buildings are constructed. There is even a concept of low-temperature district heating (LTDH), or 4th generation district heating which involve a lot of scholars. In Ref. [4] for a $\mathrm{LTDH}$, design supply temperature is from 65 to $75^{\circ} \mathrm{C}$, and the return temperature is fixed at $35^{\circ} \mathrm{C}$. Besides, leaks [5] may lead to consumer's dissatisfaction and possible disconnections from the network in order to switch to, for instance, a heat pump which would seem more cost efficient for the consumer at that point [6]. Sayegh et al. [7] showed the three main considerations when determining emissions from heat pump based DH systems: the driving energy, heat pump technologies and the heat sink characteristics. But for the other electricity types, higher seasonal coefficient of performance is often better from the point of an environmental impact [8]. The specific investment costs for the heat pumps include also installation costs and may vary from building to building due to economies of scale [9]. These prices are obtained from a heat pump manufacturer, and typically do not include realistic prices of water treatment representing almost half of operational costs [10]. In Ref. [11], authors proposed a quantitative metric to evaluate the potential for buildings to share waste heat including this generated by a heat pump. Plenty of authors [12-14] applied optimization methods to find the best solution in field of DH. In Ref. [15], the objective of the dynamic optimization was to minimize the supply temperature at a plant. In Russia [16] and China [17], sensors of a SCADA system are typically located at inlets and outlets of a central plant and a group substation measuring network temperature and pressure only. However, to obtain satisfactory detecting results with acceptable accuracy, leak location techniques need adequate monitoring data [18]. To fulfill this need Bjornebo et al. [19] developed a software for pulling together data from diverse sources. The relationship between the outdoor temperature and DH network temperature is also evident from Ref. [20] that presents a clear difference in actual and design temperature curves. In Ref. [21], the statespace model, an efficiently quantitative method, is applied to estimate the state probabilities of a repairable heat distribution network under different outdoor temperature. The load requirements may be even not met by the heating capacity of a DH system when the outside temperature extremely decreases [22]. The three options

\footnotetext{
* Corresponding author: man_csv@hotmail.com
} 
presented by Hou et al. [23] are different not only in the configuration mode of centralized system but also in the terminals on demand side. Ref. [24] covers both the results obtained by the design optimization of a $\mathrm{DH}$ system as well as the assessment of the impact of demand side measures. As we consider a heat pump typically fed by electricity with variable price a thermal energy storage unit is supposed to be connected in parallel, in order to cover rare heat peaks [25].

\section{Materials\&Methods}

Surveyed investment in a transmission line to avoid penalties on disturbances is projected to have an original supply temperature of $150^{\circ} \mathrm{C}$ and is denoted as Case- 1 . The second idea (Case-2) envisages the possibility of increasing the supply temperature in peak load periods during the heating season to limit a size of a heat pump. Another option is to use a heat pump for domestic hot water (DHW) supply, refer to Fig. 1.

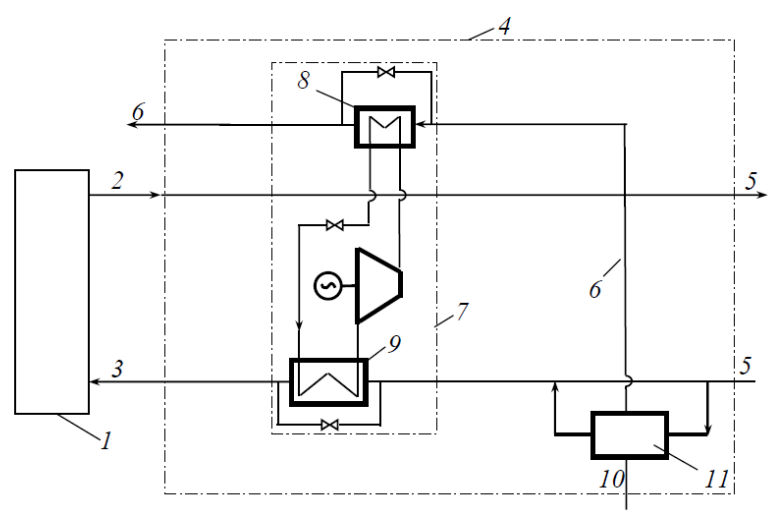

Fig. 1. Configuration of a DH system. (1) central plant, (2) supply line, (3) return line, (4) substation borders, (5) SH system, (6) DHW supply, (7) borders of a ground-source heat pump, (8) condenser, (9) evaporator (the second one, intended for back-up purposes and for a heat pump start-up), (10) cold water supply, (11) heat exchanger.

To demonstrate the benefit from the reconstruction in a DH network, 3 more configurations of energy supply method for an urban district are carried out. In Case-3, we assume in-room terminal systems are installed in some specified buildings. Case-4 assumes maintaining an ordinary DH network without using any energyefficient alternative and significant repair which means that the system continuous working 'as is'. The scheme of energy supply method in line with LTDH concept is described in Case-5.

\section{Case study}

All modeling was performed on the base of the DH system located in Omsk, Russia, where the DH network temperature requirements are not met and design outdoor temperature of extreme $-37^{\circ} \mathrm{C}$ is. Fig. 2 presents the variation of the water temperature at the plant sensors.

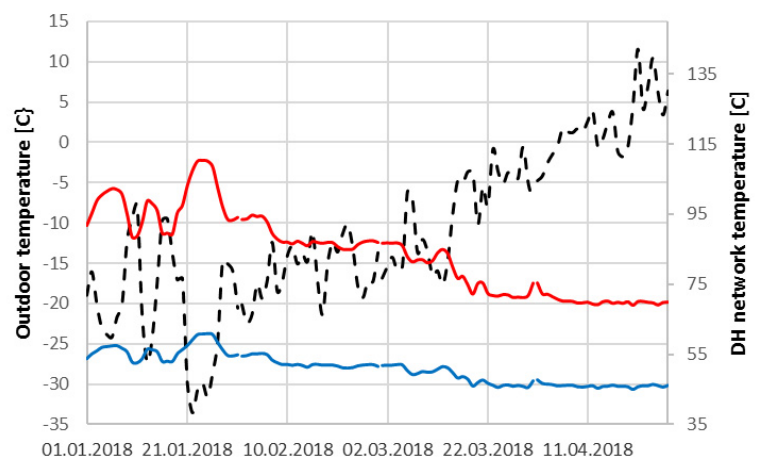

Fig. 2. Actual state - measurement data. Dash line represents outside temperature.

The top plot shows the district water temperature at the outlets of the central plant (supply temperature). The bottom plot shows the same at the inlets (return temperature).

\section{Results}

\subsection{Pipe refurbishment (Case-1)}

Retrofitting of the distribution system makes possible to run system at high temperature as was initially designed. As known [26], when less heating is supplied or the value of return temperature is increased, the system economy degrades. Considering the impact of demand side measures within the distribution system's refurbishment, the result can be observed in Ref. [6]. Hence, consumers with solar thermal collectors could be considered as prosumers [8], which means feeding the excess heat into the network.

\subsection{Installing a heat pump (Case-2)}

Higher seasonal coefficient of performance is often better from the point of an environmental impact [8]. In a heat pump, the electricity is typically used up to 90 percent. The plots in Fig. 3 indicate a discontinuity in heat demand distribution when approximately half the total load is reached.

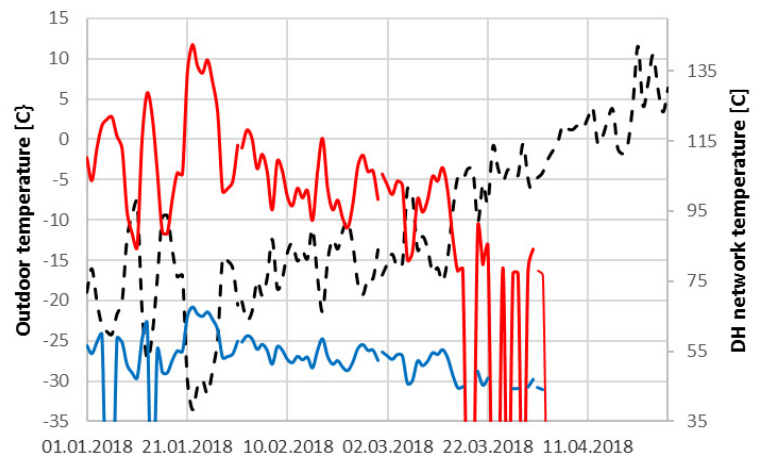

Fig. 3. While the temperature level during outdoor temperature $-5^{\circ} \mathrm{C}$ or below system's behavior is not changing (see Fig. 2), otherwise DH should stop which is indicated as a drop below the chart's lower bound. 
However, heat pumps could affect the network operational parameters, which is an emerging topic within the bibliography [7,9]. In Ref. [4] the design supply temperature is from 65 to $75^{\circ} \mathrm{C}$, at this condition, the seasonal coefficient of performance is in the range of $0.58-0.62$ with the load ratio from 50 to $95 \%$. We treat this as the guideline values for further study.

\subsection{Retrofitting to in-room terminal systems (Case-3)}

Another option is to use of in-room terminal systems to provide heating to individual zones. As well as in Ref. [19] the DH system is sized for indoor temperature of $18.3^{\circ} \mathrm{C}$.

\subsection{Maintaining the system in a current mode (Case-4)}

In the past, improper construction or insufficient operation\&maintenace, were often used for overall operating economy. Systems are currently expected to operate with limited supply temperature of $110-115^{\circ} \mathrm{C}$ (refer to Fig. 2), which is acceptable except peak load conditions. For general use, in places where the public may touch the pipes, the current operating situation is as shown in Fig. 4.

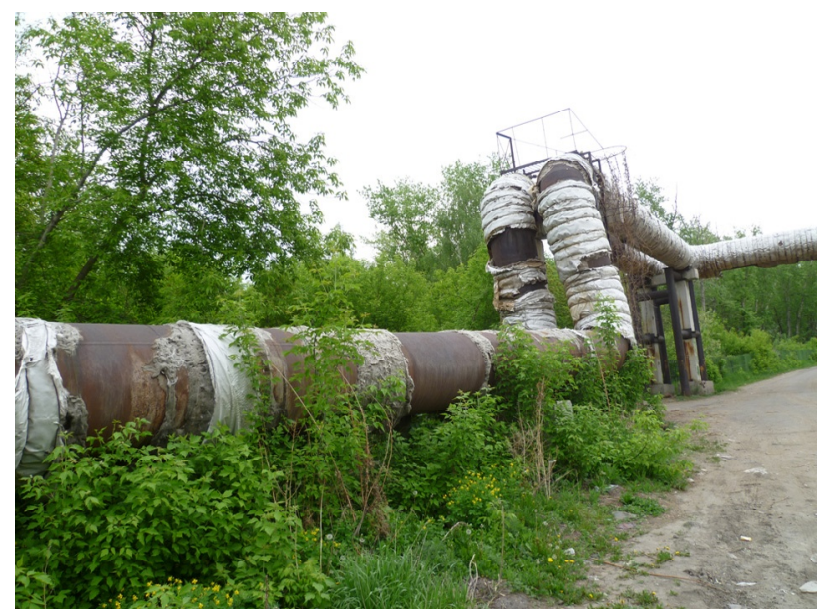

Fig. 4. Length with poor insulation.

Ayele et al. [2] presented a method to obtain end point temperatures of water in each pipe. The method is based on values of supply and return temperatures at each hub, together with the values of pipe flow rates. Results presented by Hou et al. [23] are related to the specific case study as well. For instance, they conclude that an option with $\mathrm{Li}-\mathrm{Br}$ absorption refrigeration units performs better in terms of $\mathrm{CO}_{2}$ emission reduction although an option with air-handling units is the best from the energy conservation's point of view.

\subsection{LTDH implementation (Case-5)}

The LTDH concept represents a paradigm shift in DH development and features a low supply temperature and smart control. Firstly, this is obviously costly especially because pipe replacement for larger dimensions requires much more investments. Secondly, different energy storage units should also be integrated in such a network as they are required for system function during hours of peak demand. Thirdly, to stabilize the heat demand during cold winter days, buildings are advocated to improve the secondary load structure [24]. Finally, it still cannot be determined whether LTDH can satisfy the urban demand increase caused by the construction of high-rise buildings and industrial development [28].

This research indicates location of a heat pump and also shows how the piping system will be offset to allow the normal operation [29].

\section{Conclusions}

The tool can be used as a base for development by putting ideas on the network elements and researching a case that could minimize distribution losses, production costs and primary energy [30]. The main limitation of the results of study is the fact that the investments and technical challenges of the energy renovations in the buildings were not taken into consideration [31]. Generally, this may be one of the key barriers for the feasibility of DH systems - and even more for LTDH because of the need to involve the holders and the significance of the costs that are required [32].

\section{References}

1. Kuprys, A. \& Gatautis, R. Comparison refurbishment models of district heating networks. J. Civ. Eng. Manag. 20, 11-20 (2014).

2. Ayele, G. T., Haurant, P., Laumert, B. \& Lacarrière, B. An extended energy hub approach for load flow analysis of highly coupled district energy networks: Illustration with electricity and heating. Appl. Energy 212, 850-867 (2018).

3. Cai, H., You, S., Wang, J., Bindner, H. W. \& Klyapovskiy, S. Technical assessment of electric heat boosters in low-temperature district heating based on combined heat and power analysis. Energy 150, 938-949 (2018).

4. Im, Y.-H. \& Liu, J. Feasibility study on the low temperature district heating and cooling system with bi-lateral heat trades model. Energy 153, 988-999 (2018).

5. Wang, N. et al. Hydraulic resistance identification and optimal pressure control of district heating network. Energy Build. (2018). doi:10.1016/J.ENBUILD.2018.04.003

6. Andrić, I., Fournier, J., Lacarrière, B., Le Corre, O. \& Ferrão, P. The impact of global warming and building renovation measures on district heating system techno-economic parameters. Energy (2018). doi:10.1016/j.energy.2018.03.027

7. Sayegh, M. A. et al. Heat pump placement, connection and operational modes in European district heating. Energy Build. 166, 122-144 (2018). 
8. Brange, L., Englund, J. \& Lauenburg, P. Prosumers in district heating networks - A Swedish case study. Appl. Energy 164, 492-500 (2016).

9. Vivian, J. et al. Evaluating the cost of heat for end users in ultra low temperature district heating networks with booster heat pumps. Energy (2018). doi:10.1016/j.energy.2018.04.081

10. Junussova, L. R., Abildinova, S. K., Aliyarova, M. B., Chicherin, S. V. \& Junussov, T. J. The means to improve water treatment and to enhance power engineering performance of the water source heat pump. Energ. Proc. CIS High. Educ. Institutions Power Eng. Assoc. 61, 372-380 (2018).

11. Zarin Pass, R., Wetter, M. \& Piette, M. A. A thermodynamic analysis of a novel bidirectional district heating and cooling network. Energy 144, 20-30 (2018).

12. Wang, H., Wang, H., Zhou, H. \& Zhu, T. Modeling and optimization for hydraulic performance design in multi-source district heating with fluctuating renewables. Energy Convers. Manag. 156, 113-129 (2018).

13. Tunzi, M., Boukhanouf, R., Li, H., Svendsen, S. \& Ianakiev, A. Improving thermal performance of an existing UK district heat network: A case for temperature optimization. Energy Build. 158, 15761585 (2018)

14. Delangle, A., Lambert, R. S. C., Shah, N., Acha, S. \& Markides, C. N. Modelling and optimising the marginal expansion of an existing district heating network. Energy 140, 209-223 (2017).

15. Schweiger, G., Larsson, P.-O., Magnusson, F., Lauenburg, P. \& Velut, S. District heating and cooling systems - Framework for Modelica-based simulation and dynamic optimization. Energy 137, 566-578 (2017).

16. Chicherin, S. V. Unlocking a potential of district heating network efficient operation and maintenance by minimizing the depth of a trench system. Bull. Tomsk Polytech. Univ. Geo Assets Eng. 328, (2017).

17. Zhou, S., O'Neill, Z. \& O’Neill, C. A review of leakage detection methods for district heating networks. Appl. Therm. Eng. 137, 567-574 (2018).

18. Chicherin, S. V. New approach to determination of corrosion damage degree of pipeline system elements. Bull. Tomsk Polytech. Univ. Geo Assets Eng. 327, (2016).

19. Björnebo, L., Spatari, S. \& Gurian, P. L. A greenhouse gas abatement framework for investment in district heating. Appl. Energy 211, 1095-1105 (2018).

20. Chicherin, S. Survey of District Heating System Operational Temperatures: Return Line-Based View. J. Sci. Eng. Res. 5, 219-224 (2018).

21. Shan, X., Wang, P. \& Lu, W. The reliability and availability evaluation of repairable district heating networks under changeable external conditions. Appl. Energy 203, 686-695 (2017).
22. Chicherin, S. Network Temperatures and Flow Rate: Case Study of District Heating in Canberra, Australia. Int. J. Energy Environ. Sci. 3, 61-68 (2018).

23. Hou, J. et al. Implementation of expansion planning in existing district energy system: A case study in China. Appl. Energy 211, 269-281 (2018).

24. Coss, S., Verda, V. \& Le-Corre, O. Multi-objective optimization of District Heating Network model and assessment of Demand Side Measures using the load deviation index. J. Clean. Prod. (2018). doi:10.1016/j.jclepro.2018.02.083

25. Badami, M., Fonti, A., Carpignano, A. \& Grosso, D. Design of district heating networks through an integrated thermo-fluid dynamics and reliability modelling approach. Energy 144, 826-838 (2018).

26. Kabalina, N., Costa, M., Yang, W. \& Martin, A. Impact of a reduction in heating, cooling and electricity loads on the performance of a polygeneration district heating and cooling system based on waste gasification. Energy 151, 594-604 (2018).

27. Chicherin, S. District Heating System Performance Charasteristics (Omsk, Russia, Nov. 2017). Mendeley Data, v1 (2017). doi:10.17632/4tgypy6hhf.1

28. Zbaraz L.I., Chicherin S. V. Configuring a district heating plant under reconstruction: optimum quantity of boiler units. Bulletin of the Tomsk Polytechnic University. Geo Assets Engineering. $\begin{array}{lllll}2019 . & \text { V. } & 330 . & 7 . & 62-70\end{array}$ doi:10.18799/24131830/2019/7/2177

29. Junussova, L. R., \& Chicherin, S. V. (2019). Improving a water treatment and a heating performance of the water-to-water heat pump: misallocation and available solutions. IOP Conference Series: Earth and Environmental Science, 288, 012092. doi:10.1088/17551315/288/1/012092

30. Junussova, L. R., Chicherin, S. V. (2019). Method of Aluminum Salts Extraction from Wastewater Using Desalination Technology: Syr Darya River Case Study. IOP Conference Series: Earth and Environmental Science, 288, 012008. doi:10.1088/1755-1315/288/1/012008

31. Chicherin, S. V. Comparison of a district heating system operation based on actual data - Omsk city, Russia, case study. International Journal of Sustainable Energy, 2019, 38(6), 603-614. doi:10.1080/14786451.2018.1548466

32. Chicherin, S., Volkova, A., \& Latõšov, E. GISbased optimisation for district heating network planning. Energy Procedia, 2018, 149, 635-641 